\title{
FIGNL1 is overexpressed in small cell lung cancer patients and enhances NCI-H446 cell resistance to cisplatin and etoposide
}

\author{
JIAN MA $^{1^{*}}$, JIANLEI LI $^{2 *}$, XIAOLING YAO ${ }^{2}$, SHUANGJUN LIN ${ }^{2}$, YE GU $^{3}$, JIANFANG XU $^{1}$, \\ ZIXIN DENG ${ }^{2}$, WEI MA ${ }^{2}$ and HAIPING ZHANG ${ }^{1}$
}

\author{
${ }^{1}$ Department of Oncology, Shanghai Pulmonary Hospital, Tongji University School of Medicine, Shanghai 200092; \\ ${ }^{2}$ State Key Laboratory of Microbial Metabolism, and School of Life Sciences and Biotechnology, \\ Shanghai Jiao Tong University, Shanghai 200240; ${ }^{3}$ Department of Endoscopy, Shanghai Pulmonary Hospital, \\ Tongji University School of Medicine, Shanghai 200092, P.R. China
}

Received July 4, 2016; Accepted November 18, 2016

DOI: 10.3892/or.2017.5483

\begin{abstract}
Abnormal DNA repair plays an important role in tumor occurrence, progression and resistance to therapy. Fidgetin-like 1 ( $F I G N L 1)$ expression was assayed in 42 small cell lung cancer (SCLC) and 45 normal lung specimens from Chinese patients by qRT-PCR. Notably, FIGNL1 was upregulated by 1.5 -fold in the SCLC specimens compared to that noted in the normal counterparts. The SCLC cell line NCI-H446 that overexpresses FIGNL1 was adopted to explore the biological significance of FIGNL1 in SCLC. Even when FIGNL1 expression was suppressed by up to $48.6 \%$, H446 cell growth was increased by only $10-16 \%$. Although no significant changes in cell cycle distribution were observed in the H446 cells, the levels of cyclin E1 and CDK2, key cell cycle regulators, were significantly reduced. After downregulation of $F I G N L 1$ expression by $13.5 \%$ in the $\mathrm{H} 446$ cells, the cells were $61.8 \%$ ( $24 \mathrm{~h}$ ) to $29.1 \%$ (48 h) more sensitive to etoposide and cisplatin, respectively, consistent with the FIGNL1 function of DNA doublestrand repair. The sensitivity of $\mathrm{H} 446$ cells to etoposide and cisplatin was negatively correlated with FIGNL1 expression. Meanwhile, an obvious positive correlation between DNA damage severity and the sensitization effect of FIGNL1 knockdown was observed. Since FIGNL1 is essential in the
\end{abstract}

Correspondence to: Dr Wei Ma, State Key Laboratory of Microbial Metabolism, and School of Life Sciences and Biotechnology, Shanghai Jiao Tong University, 800 Dongchuan Road, Shanghai 200240, P.R. China

E-mail:wma@sjtu.edu.cn

Dr Haiping Zhang, Department of Oncology, Shanghai Pulmonary Hospital, Tongji University School of Medicine, 507 Zhengmin Road, Shanghai 200092, P.R. China

E-mail: zhp7341@sina.com

*Contributed equally

Key words: small cell lung cancer, FIGNL1, DNA repair, homologous recombination repair pathway, chemotherapy resistance homologous recombination (HR) pathway, these findings suggest that abnormal activation of the HR pathway featured by FIGNL1 overexpression contributes to rapid progression and relapse of SCLC in addition to chemotherapy resistance. Further research assessing the functions and mechanisms of FIGNL1, and other HR pathway genes may disclose unique pathological characteristics of SCLC, and help identify potential therapeutic targets and biomarkers.

\section{Introduction}

Small cell lung cancer (SCLC), accounting for $\sim 15-20 \%$ of all lung cancer cases, is characterized by its neuroendocrine origin, rapid development and early metastasis. SCLC has the lowest differentiation and highest malignant degree among lung cancers (1). Approximately $70 \%$ of SCLC patients are diagnosed at a late stage with accompanying metastasis. Therefore, the 5-year survival rate of patients with SCLC is only $5-10 \%$ (2). The development of novel targeted therapeutics for SCLC is one of the promising strategies by which to improve the outcome of SCLC treatment.

Genomic instability and high frequency of p53 mutations are two common characteristics of most human tumors (3). Genomic instability is an important impetus for tumor occurrence and development $(4,5)$. Genomic instability is principally acquired through reprogramming the DNA repair pathway by oncogenes (6).

Among all types of DNA damage, DNA double-strand breaks (DSBs) pose the greatest threat to cells (3). DSBs not timely and properly repaired lead to chromosomal rearrangements, aneuploidy and other serious genomic mutations (7). An aberrant DSB repair pathway diminishes the fidelity and efficiency of DNA repair; therefore, tumors can significantly gain genomic instability to accelerate progression (8). Meanwhile, abnormal enhancement of specific DNA repair pathways can undoubtedly lead to tumor cell radioresistance and chemoresistance, since radiation and most first-line chemotherapeutics kill tumor cells mainly by DNA damage (9).

Research has demonstrated that certain DNA repair pathways, such as transcription-coupled and expression-linked repairs (10), are inactivated, while others are upregulated in 
various SCLC cell lines. For example, PARP expression in SCLC is 2.06 times higher than that in NSCLC (11). Thus, differences in DNA repair pathways and repair ability between tumor and normal cells have been increasingly assessed to identify promising targets $(2,12)$.

Homologous recombination (HR) repairs DNA doublestrand breaks with high fidelity. RAD51, the core protein of HR, is expressed 4-6 times higher in the majority of tumor cells both at the gene and protein levels, compared with corresponding normal cells, with its activity increasing by up to 840-fold (13). Abnormal expression of RAD51 can lead to diminished fidelity of HR repair, and promote occurrence of translocation and other chromosome mutations (14). Due to the close correlation between the aberrant activity of RAD51 and tumor occurrence, regulation of the activity of RAD51 has attracted increased attention from scientists.

Fidgetin-like 1 (FIGNL1) belongs to the AAA-ATPase protein family (15), and plays an important role in meiosis and mitosis $(16,17)$. FIGNL1 is an indispensable component of HR, specifically interacting with RAD51 via its conserved RAD51 binding domain (18). The above findings indicate that FIGNL1 can directly regulate the activity of RAD51 and indirectly modulate that of HR in DNA DSB repair. The present study aimed to assess FIGNL1 in SCLC patients and cell lines to explore the function of HR in SCLC.

\section{Materials and methods}

Patients and tissue samples. Specimens were collected from patients who underwent surgical resection for lung cancer or suspected lung cancer patients through bronchoscopic biopsy at Shanghai Pulmonary Hospital from 2013 to 2015, with the approval of the Ethics Committee of Tong Ji University. All patients involved in the present study had provided written informed consent for the use of their tissue samples in the present study. The specimens that were confirmed to be SCLC or normal (tumor negative) by pathological examination were used for the following experiments. Detailed clinical information is shown in Table I. All specimens were immediately preserved in RNAstore reagent (Tiangen Biotech, Beijing, China) at $4^{\circ} \mathrm{C}$ until total RNA extraction.

Cell culture. The human SCLC NCI-H446 cell line was obtained from the Cell Bank of the Chinese Academy of Sciences and was cultured in RPMI-1640 medium (HyClone, Logan, UT, USA) containing 10\% fetal bovine serum (FBS) (Gibco, Grand Island, NY, USA). The human embryonic lung fibroblast MRC-5 cell line was a kind gift from Professor Zhiyong Li at the College of Life Science and Technology, Shanghai Jiao Tong University, and was cultured in Minimum essential medium (MEM) containing 10\% FBS. The Platinum-A Retroviral Packaging Cell Line was a kind gift from Professor Songcheng Zhu of Tongji University. Culture medium was Dulbecco's modified Eagle's medium (DMEM) containing $10 \%$ FBS, with blasticidin and puromycin (Sigma-Aldrich, St. Louis, MO, USA) added to final concentrations of 10 and $1 \mu \mathrm{g} / \mathrm{ml}$, respectively.

Chemical and reagents. The chemicals used in the present study were purchased from Sigma-Aldrich.
Table I. Specimens assayed for FINGLI expression.

\begin{tabular}{lccc}
\hline Variables (n) & Normal & SCLC & P-value \\
\hline Total & 45 & 42 & \\
Gender & & & 0.2853 \\
Male & 34 & 36 & \\
Female & 11 & 6 & \\
Age (years) & & & \\
<60 & 26 & 18 & \\
$>60$ & 19 & 24 & \\
TNM stage & & & \\
I-IIa & - & 0 & \\
IIb-IIIa & - & 13 & \\
IIa-IV & - & 29 & \\
\hline
\end{tabular}

FINGL1, fidgetin-like 1; SCLC, small cell lung cancer; TNM, tumornode-metastasis.

Total RNA extraction and real-time PCR. Total RNA extraction kit was used for total RNA extraction. Approximately $1,000 \mathrm{ng}$ total RNA was reverse transcribed in $20 \mu \mathrm{l}$ volume using FastQuant cDNA First Chain Synthesis kit (both from Tiangen) according to the manufacturer's instructions. Quantitative real-time PCR (qPCR) was performed using Super Real PreMix Plus (SYBR-Green) (Tiangen) on Eppendorf Mastercycler ep realplex4, with $G A P D H$ as an internal control. The PCR program was as following: $3 \mathrm{~min}$ at $95^{\circ} \mathrm{C}$, followed by 40 cycles at $95^{\circ} \mathrm{C}$ for $30 \mathrm{sec}, 60^{\circ} \mathrm{C}$ for $30 \mathrm{sec}$ and $72^{\circ} \mathrm{C}$ for $15 \mathrm{sec}$, and last step was the melting curve analysis program. All experiments were independently performed three times, and three replicates each time. The following primers were used: 5'-TCCTGCACCACCAACTGCTT-3' (forward) and 5'-GGGGCCATCCACAGTCTTCT-3' (reverse) for FIGNL1; 5'-CTCAGCGTGCATCAGGGTCT-3' (forward) and 5'-CTGCTCTCCCCCATCTTGCT-3' (reverse) for GAPDH; 5'-GTTCCTCCTTGGAAAGCAAACAGTA-3' (forward) and 5'-CAGGGCATCTTCACGCTCTATTT-3' (reverse) for cyclin A2; 5'-AGAAATGGCCAAAATCGA CA-3' (forward) and 5'-CCCGGTCATCATCTTCTTTG-3' (reverse) for cyclin E1; 5'-TATGCCTGATTACAAGCCAA GTTTC-3' (forward) and 5'-GATAACAAGCTCCGTCCATCT TCAT-3' (reverse) for CDK2; 5'-CATTGTTGTGTTTCACT GCGAGTTT-3' (forward) and 5'-GGACATACAGCTCAGG GTAGTGGAG-3' (reverse) for cdc25A. Relative gene expression was calculated by the $2^{-\Delta \mathrm{Ct}}$ method.

Western blotting. Cells were lysed using RIPA lysis solution (Tiangen Biotech). After the protein concentrations were determined, the protein samples were separated by $10 \%$ SDS-PAGE, transferred onto $0.45-\mu \mathrm{m}$ polyvinylidene fluoride (PVDF) membranes (Millipore, Darmstadt, Germany) and probed with relevant antibodies. Anti-FIGNL1 (cat. no. 76041-APl; 1:1,000) and anti-GAPDH (cat. no. 10494-1-AP; 1:2,000) were obtained from ProteinTech (Chicago, IL, USA). After incubation with the primary antibody overnight at $4^{\circ} \mathrm{C}$, the membranes were washed with Tris-buffered saline with 
A

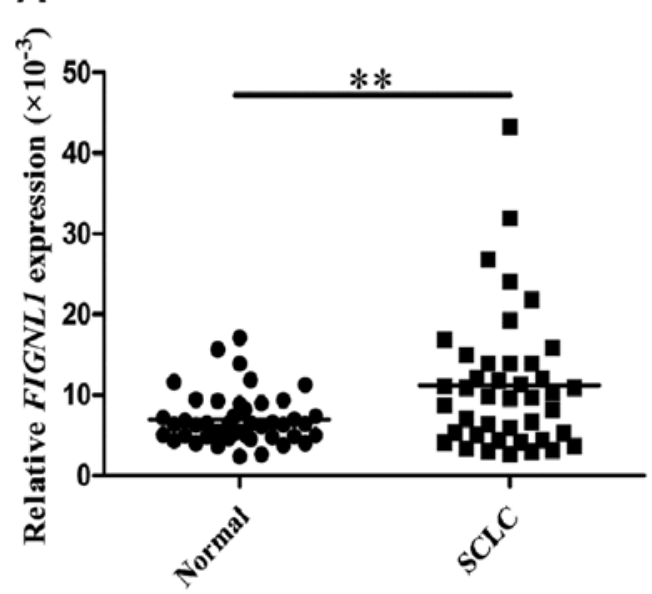

B

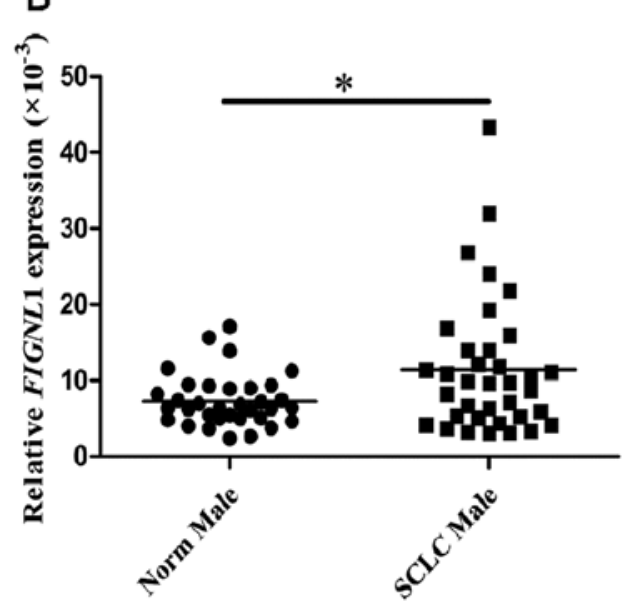

Figure 1. FIGNL1 is overexpressed in the SCLC patients. (A) Comparison of FIGNL1 expression in normal lung and SCLC specimens from both male and female patients; ${ }^{* *} \mathrm{P}=0.004$. (B) Comparison of FIGNL1 expression in normal lung and SCLC specimens from male patients; ${ }^{*} \mathrm{P}=0.014$.

Tween-20 (TBST) three times, 5 min each. HRP-labeled secondary antibodies (cat. no. 111-035-003; 1:2,000) were obtained from Jackson ImmunoResearch (West Grove, PA, USA). After incubation with the secondary antibody for $2 \mathrm{~h}$ at room temperature, the membranes were washed for three time with TBST for 10 min each, Protein bands were detected by enhanced chemiluminescence (ECL; Sigma-Aldrich) and quantitated using Gel-Pro Analyzer 4.0 (Media Cybernetics, Rockville, MD, USA), and the results were obtained from three independent experiments.

shRNA and SCLC cell transfection. Short hairpin RNA (shRNA) targeting FIGHL1 and a negative control were designed by Origene Technologies, Inc. (Rockville, MD, USA). shRNA sequences for FIGHL1 were: 5'-AGCACATCCAGT TGATGAGCGTCTGAAGA-3' for shFIGNL1-B, 5'-CAGA AGCTTCAGCCAGGAAACAGATAGTA-3' for shFIGNL-D, and 5'-GCACTACCAGAGCTAACTCAGATAGTACT-3 for sh-control.

H446 cells were transfected using $0.45 \mu \mathrm{M}$ filtered and Polybrene supplemented ( $8 \mu \mathrm{g} / \mathrm{ml}$ final concentration) culture media of the Platinum-A Retroviral Packaging Cell Line transfected with the shRNA plasmid for $48 \mathrm{~h}$ by Lipofectamine 2000. H446 cells were screened with complete culture medium containing puromycin at $1.0 \mu \mathrm{g} / \mathrm{ml}$ for 6 days Afterwards, the cells were cultured with complete medium with $0.5 \mu \mathrm{g} / \mathrm{ml}$ puromycin.

Cell cycle analysis. The cells were cultured for $\sim 2$ days following synchronization for $12 \mathrm{~h}$. Then, the cells were collected, washed with PBS and fixed with $75 \%$ ethanol at $-20^{\circ} \mathrm{C}$ overnight. After incubation with $0.1 \mathrm{mg} / \mathrm{ml}$ RNase $\mathrm{A}$ at $37^{\circ} \mathrm{C}$ for $30 \mathrm{~min}$ and staining with $40 \mu \mathrm{g} / \mathrm{ml}$ PI (Sigma, St. Louis, MO, USA) in the dark for $30 \mathrm{~min}$, DNA content was detected by flow cytometry (FACSCalibur; Becton-Dickinson, San Jose, CA, USA). Cell cycle distribution was analyzed and calculated by ModFit (Verity Software House, Topsham, ME, USA).

Cell proliferation assay. Cells were plated at $3 \times 10^{3} /$ well in 96-well plates. MTT assay was adopted to assess cell viability.
Absorbance was measured on an EnSpire 2300 microplate reader (Perkin Elmer, Waltham, MA, USA) at $550 \mathrm{~nm}$. For drug sensitivity assay, cells were seeded in 96-well plates at a density of $3 \times 10^{3}$ cells/well and cultured for $24 \mathrm{~h}$. Then, the cells were exposed to $0,20,40,80$ and $160 \mu \mathrm{M}$ etoposide, respectively, for $24 \mathrm{~h}$, or $0,1.25,2.5,5,10$ and $20 \mu \mathrm{M}$, respectively, for $48 \mathrm{~h}$; cisplatin was assayed at $0,2,4,8,16$ and $32 \mu \mathrm{M}$, respectively, for $24 \mathrm{~h}$, or $0.5,1,2,4$, and $8 \mu \mathrm{M}$, respectively, for $48 \mathrm{~h}$. Cell survival was measured by the MTT assay, and half maximal inhibitory concentration $\left(\mathrm{IC}_{50}\right)$ values of etoposide or cisplatin were calculated by GraphPad Prism 5.0.

Statistical analysis. Statistical analysis was performed using SPSS 17.0 or GraphPad Prism 5.0. Two groups of data, such as FIGNL1 expression between normal and SCLC specimens, was analyzed using a t-test to determine statistical significance. For three or more groups of data, such as comparison of FIGNL1 expression among the different $\mathrm{H} 446$ transfected cells, one-way analysis of variance (ANOVA) with Bonferoni post test was adopted. Results are presented as mean $\pm \mathrm{SD}$. $\mathrm{P}<0.05$ was considered to indicate a statistically significant result.

\section{Results}

FIGNL1 expression in SCLC specimens. A total of 45 normal lung samples was assessed, from 34 male and 11 female patients, respectively. In these specimens, the relative expression level of FIGNL1 was $6.965 \pm 3.204 \times 10^{-3}$. Meanwhile, 42 SCLC samples from 36 males and 6 females were assessed, and yielded a value of $11.197 \pm 8.466 \times 10^{-3}$ (Table I). Comparison of the FIGNL1 expression levels between normal and SCLC samples showed a statistical significance ( $\mathrm{P}=0.004$; Fig. 1A). A similar result was obtained for comparison between normal and SCLC specimens from the male patients $(\mathrm{P}=0.014$; Fig. 1B). No significant difference in FIGNL1 expression levels was observed between age groups below and above 60 years and early and advanced stage groups (data not shown).

FIGNL1 expression in SCLC and normal lung fibroblast cell lines. The FIGNL1 transcription level was 3.46-fold 
A

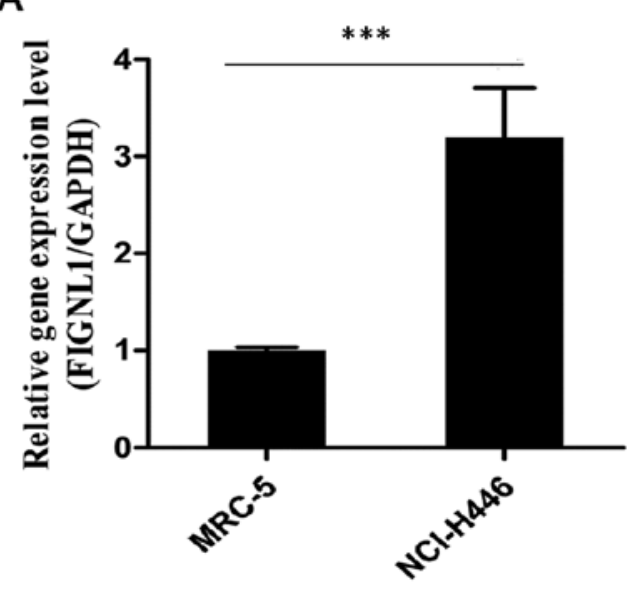

B

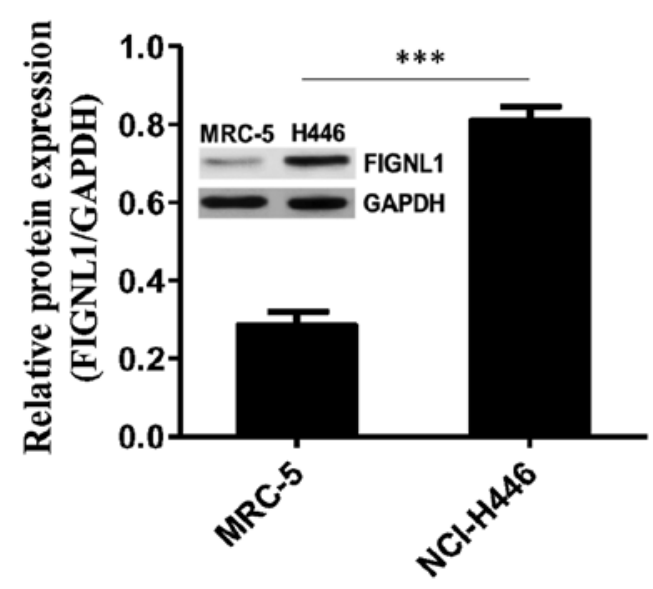

Figure 2. FIGNL1 expression was higher in the NCI-H446 SCLC cell line than that noted in the MRC-5 normal cell line at both the mRNA and protein levels. (A) Comparison of FIGNL1 expression in MRC-5 and NCI-H446 cell lines; ${ }^{* * *} \mathrm{P}<0.001$. (B.) Comparison of FIGNL1 in H446 and MRC-5 cells by western blotting; ${ }^{* * *} \mathrm{P}<0.001$. Values provided were calculated from three independent experiments.

in the SCLC H446 cells [9.83 $\pm 0.12(\Delta \mathrm{Ct})]$ compared to this level in the normal lung fibroblast MRC-5 cells $[11.13 \pm 0.04$ $(\Delta \mathrm{Ct})](\mathrm{P}<0.001$; Fig. 2A).

Moreover, FIGNL1 protein expression was assessed in the different cell lines. Notably, the FIGNL1 protein level (FIGNL1/GAPDH) in the H446 cells $(0.808 \pm 0.035)$ was 2.84 times higher compared to amounts obtained in the MRC-5 cells $(0.285 \pm 0.035)(\mathrm{P}<0.001$; Fig. $2 \mathrm{~B})$.

Effect of FIGNL1 knockdown on the growth and cell cycle distribution of $H 446$ cells. To further explore the biological function of FIGNL1 overexpression in SCLC cells, shRNA was used to silence FIGNL1 in the H446 cell line.

$\Delta \mathrm{Ct}$ values for $F I G N L 1$ were $10.81 \pm 0.11$ and $9.98 \pm 0.06$ in the H446 cells transfected with shFIGNL1-B and shFIGNL1$\mathrm{D}$, respectively. Compared to the control group $[9.77 \pm 0.10$ (shCtrl)], FIGNL1 mRNA amounts were reduced by $48.6 \%$ $(\mathrm{P}=0.006)$ and $13.5 \%(\mathrm{P}>0.05)$ in the shFIGNL1-B and shFIGNL1-D group cells, respectively (Fig. 3A). Western blot results further confirmed that the FIGNL1 protein level (FIGNL1/GAPDH) was reduced by $55.5 \%(\mathrm{P}=0.002)$ and $46.5 \%(\mathrm{P}=0.002)$, respectively, in the $\mathrm{H} 446$ cells transfected with shFIGNL1-B $(0.359 \pm 0.087)$ or shFIGNL1-D $(0.431 \pm 0.117)$ compared to the control $(0.806 \pm 0.059)$ (Fig. $3 \mathrm{~B}$ and $\mathrm{C})$.

FIGNL1 silencing slightly affects $H 446$ cell growth. Three groups of $\mathrm{H} 446$ cells with the same initial density were cultured for two days, and 13.8 and $12.5 \%$ more cells were transfected with shFIGNL1-B $(\mathrm{P}=0.0011)$ or shFIGNL1-D $(\mathrm{P}=0.0017)$, compared with the control group. After three days of culture, 12.8 and $11.5 \%$ more cells were found in the shFIGNL1-B $(\mathrm{P}=0.003)$ and shFIGNL1-D $(\mathrm{P}=0.002)$ groups compared with the control group. After culture for four days, $17.1 \%(\mathrm{P}=0.003)$ and $15.6 \%(\mathrm{P}=0.004)$ more cells, respectively, were obtained in the shFIGNL1-B and shFIGNL1-D groups compared with the control group. These findings indicated that FIGNL1 suppression slightly accelerated growth in the H446 cells (Fig. 4).
FIGNL1 silencing alters the expression of key genes involved in cell cycle regulation. To assess whether FIGNL1 expression affects the cell cycle, cyclin A2, cyclin E1, CDK2 and cdc25A expression levels were quantified in the $\mathrm{H} 446$ cells transfected with the different shRNAs.

As shown in Fig. 5, in the H446 cells transfected with shFIGNL1-D, no significant change in the expression of cyclin A2, cdc25A, cyclin E1 and CDK2 was observed. However, in the shFIGNL1-B-transfected cells, cyclin E1 and CDK2 mRNA amounts decreased by $34.94 \%(\mathrm{P}=0.016)$ and $53.03 \%(\mathrm{P}=0.018)$, respectively, at same time the expression of cyclin A2 and cdc25A remained unchanged.

Cyclin-dependent kinases (CDKs) function mainly in $\mathrm{S}$ and G1 phases of the cell cycle and most tumors abrogate the cell cycle regulatory mechanism by directly or indirectly enhancing the activity of CDKs $(19,20)$. Thus, cell cycle analysis was conducted to assess whether this downregulation impacted the H446 cell cycle.

Effect of FIGNL1 silencing on H446 cell cycle distribution. Flow cytometry was used to assess the cell cycle distribution of H446 cells transfected with the different shRNAs. As shown in Fig. 6, cell cycle distribution was not significantly different among the groups. Although, FIGNL1 knockdown greatly reduced cyclin $E 1$ and $C D K 2$ expression, it did not affect the cell cycle.

FIGNL1 silencing sensitizes H446 cells to etoposide and cisplatin. Following treatment with etoposide for $24 \mathrm{~h}$, the sensitivity to etoposide of H446 cells transfected with shFIGNL1-B or shFIGNL1-D was increased by 65.6 and $61.8 \%$, respectively, compared to the control group (Fig. 7A; Table II).

After treatment with etoposide for $48 \mathrm{~h}$, sensitivity of the H446 cells transfected with shFIGNL1-B or shFIGNL1-D to etoposide was increased by 47.8 and $24.3 \%$, respectively, compared to the control group (Fig. 7B; Table II).

Changes in the sensitivity to cisplatin in $H 446$ cells after FIGNL1 silencing. As shown in Fig. 7C and Table III, H446 


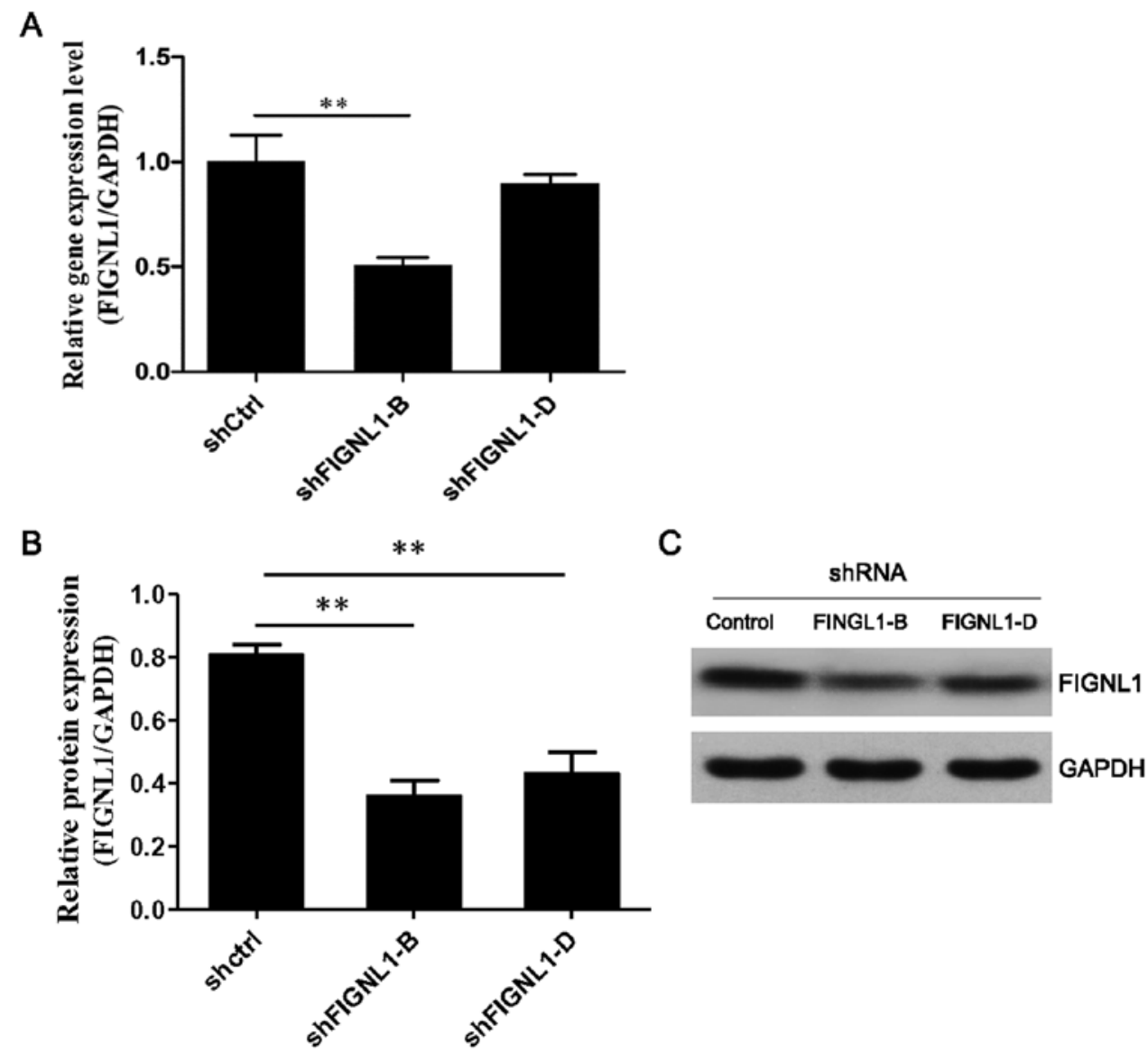

Figure 3. Suppression efficiency of different shRNAs targeting FIGNL1. (A) Comparison of FIGNL1 expression in H446 cells transfected with shRNA-ctrl, shFIGNL1-B or shFIGNL1-D. " $\mathrm{*}=0.006$. (B) FIGNL1 protein level in the H446 cells transfected with shRNA-ctrl, shFIGNL1-B or shFIGNL1-D calculated from three independent experiments; ${ }^{* *} \mathrm{P}<0.01$. (C) Western blot results of FIGNL1 protein expressed in the H446 cells transfected with shRNA-ctrl, shShFIGNL1-B or shFIGNL1-D.

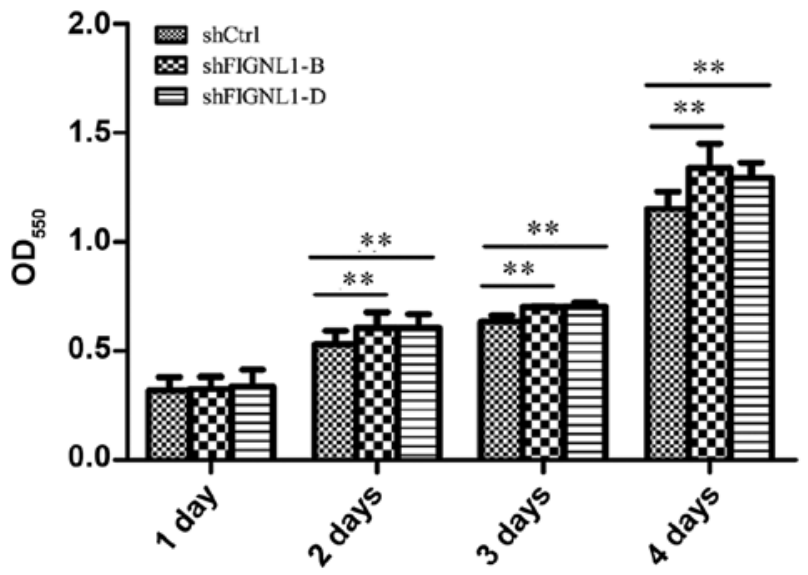

Figure 4. Comparison of cell growth among the $\mathrm{H} 446$ cells transfected with shRNA-control, shFIGNL1-B or shFIGNL1-D; ${ }^{* *} \mathrm{P}<0.01$.

cells treated with cisplatin for $24 \mathrm{~h}$ showed $\mathrm{IC}_{50}$ values of 6.463 , 5.157 and $5.446 \mu \mathrm{M}$ in the shCtrl, shFIGNL1-B and shFIGNL1D groups, respectively. Compared with the control group, sensitivity of H446 cells to cisplatin was increased by 20.1 and $15.6 \%$ after $F I G N L 1$ suppression by 48.6 or $13.5 \%$, respectively.

H446 cells treated with cisplatin for $48 \mathrm{~h}$ showed $\mathrm{IC}_{50}$ values of $1.889,1.046$ and $1.342 \mu \mathrm{M}$ in the shCtrl,

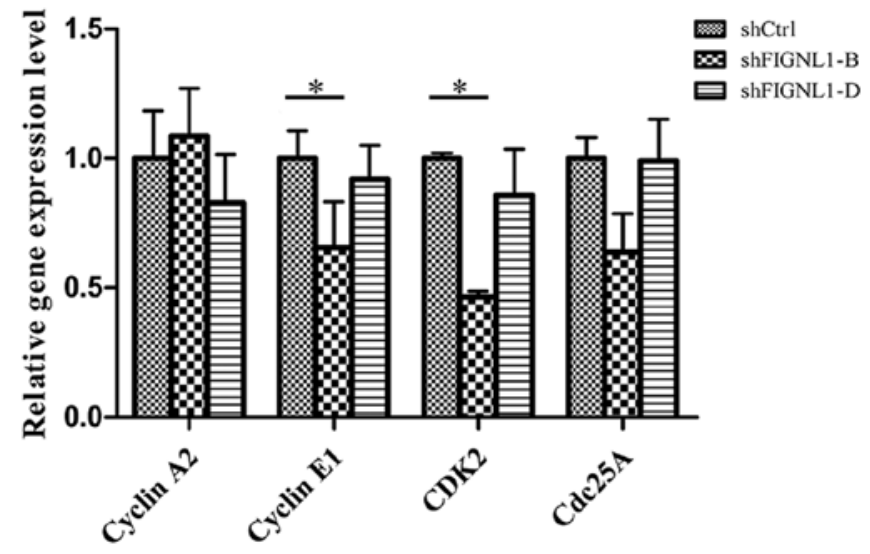

Figure 5. FIGNL1 knockdown suppressed the expression of cyclin E1, CDK2 and cdc25A in the H446 cells; " $\mathrm{P}<0.05$.

shFIGNL1-B and shFIGNL1-D groups, respectively (Fig. 7D; Table III). Compared with the control group, the sensitivity of shFIGNL1-B- and shFIGNL1-D-transfected cells to cisplatin was increased by 44.4 and $29.1 \%$, respectively.

The above results showed a negative correlation between the FIGNL1 expression level in H446 cells and H446 cell sensitivity to etoposide and cisplatin. 
A
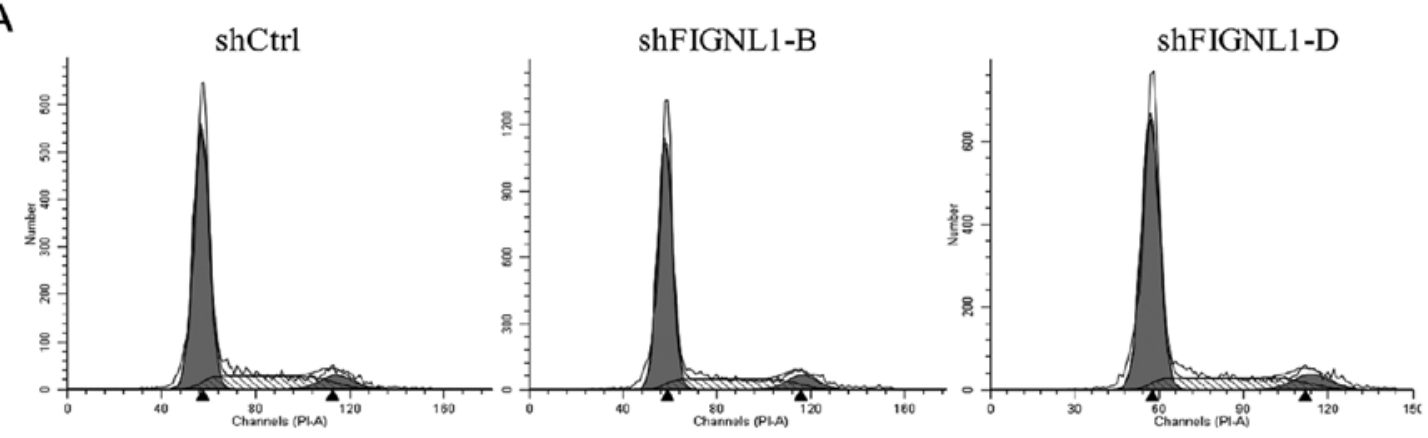

B

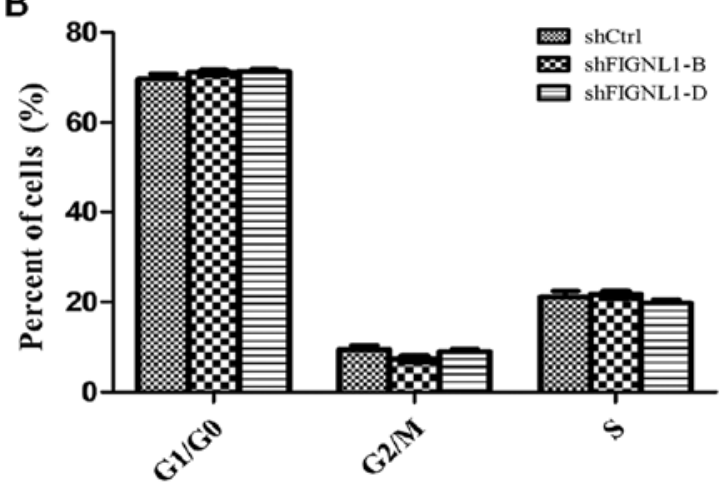

Figure 6. Inhibition of FIGNL1 expression did not result in a change in the $\mathrm{H} 446$ cell cycle distribution. (A) Cell cycle analysis of the $\mathrm{H} 446$ cells transfected with shRNA-ctrl, shFIGNL1-B or shFIGNL1-D, respectively, by FACS. (B) Mean values from three independent experiments.

A

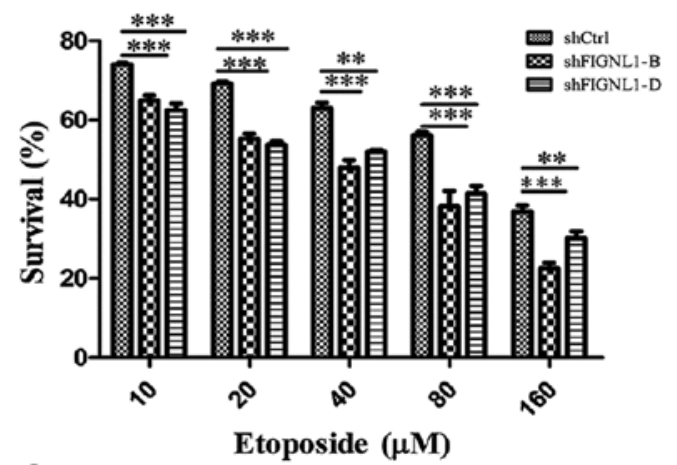

C

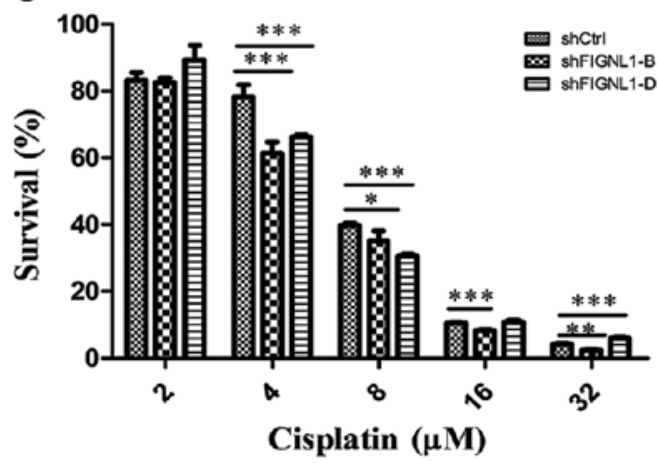

\section{B}

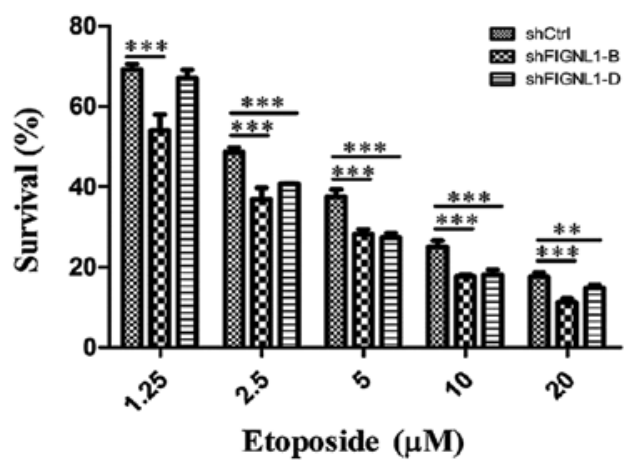

D

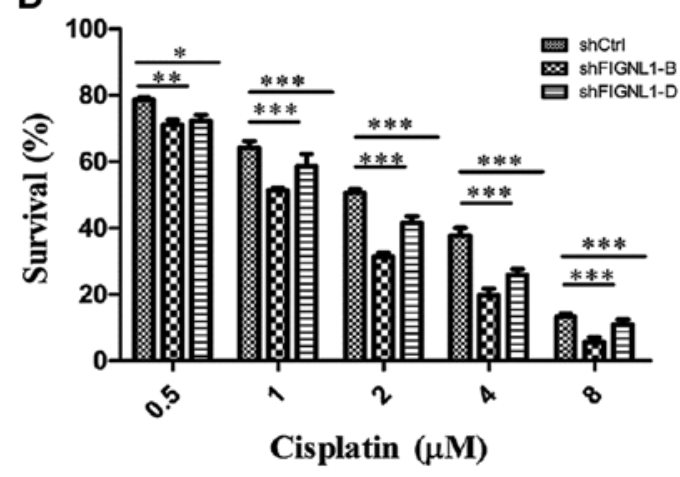

Figure 7. Inhibition of FIGNL1 expression significantly sensitizes H446 cells to etoposide and cisplatin. H446 cells transfected with shRNA-Ctrl, shFIGNL1$\mathrm{B}$ or shFIGNL1-D were treated with the indicated concentrations of etoposide for (A) $24 \mathrm{~h}$ or (B) $48 \mathrm{~h}$, respectively. H446 cells transfected with shRNA-Ctrl, shFIGNL1-B or shFIGNL1-D were treated with the indicated concentrations of cisplatin for (C) $24 \mathrm{~h}$ or $(\mathrm{D}) 48 \mathrm{~h}$, respectively; ${ }^{*} \mathrm{P}<0.05,{ }^{* *} \mathrm{P}<0.01,{ }^{* * *} \mathrm{P}<0.001$.

\section{Discussion}

Assessment of 45 normal lung and 42 SCLC clinical specimens revealed that FIGNL1 expression in the SCLC samples was
1.5 times increased in the SCLC specimens when compared to that noted in the normal lung tissue specimens.

As an AAA-ATPase protein family member (21), FIGNL1 is involved in various important cellular activities 
Table II. $\mathrm{IC}_{50}$ values of etoposide in the $\mathrm{H} 446$ cells transfected with the different shRNAs.

\begin{tabular}{lcc}
\hline Construct transfected & $\begin{array}{c}\mathrm{IC}_{50}(24 \mathrm{~h}) \\
(\mu \mathrm{M})\end{array}$ & $\begin{array}{c}\mathrm{IC}_{50}(48 \mathrm{~h}) \\
(\mu \mathrm{M})\end{array}$ \\
\hline shRNA-Ctrl & 87.44 & 2.76 \\
shRNA-FIGNL1-B & 30.10 & 1.44 \\
shRNA-FIGNL1-D & 33.39 & 2.09 \\
\hline
\end{tabular}

shRNAs, short hairpin RNAs.

Table III. IC $_{50}$ value of cisplatin in the $\mathrm{H} 446$ cells transfected with the different shRNAs.

\begin{tabular}{lcc}
\hline Construct transfected & $\begin{array}{c}\mathrm{IC}_{50}(24 \mathrm{~h}) \\
(\mu \mathrm{M})\end{array}$ & $\begin{array}{c}\mathrm{IC}_{50}(48 \mathrm{~h}) \\
(\mu \mathrm{M})\end{array}$ \\
\hline shRNA-Ctrl & 6.46 & 1.89 \\
shRNA-FIGNL1-B & 5.16 & 1.05 \\
shRNA-FIGNL1-D & 5.45 & 1.34 \\
\hline
\end{tabular}

shRNAs, short hairpin RNAs.

via regulation of microtubules, chromosome scaffold and assembly and depolymerization of other important protein complexes (22-25). FIGNL1, an indispensable member of the homologous recombination DNA repair system, plays an important role in DNA double-strand break repair through interacting with RAD51 (18). The essential function and unique mechanism of FIGNL1 in DNA repair makes it an attractive target for modulation of HR pathway activity.

Abnormalities in the DNA double-strand break repair pathway is a main contributor to cell genomic instability (8), which is an important driving force in tumorigenesis (26), development and metastasis (27). Meanwhile, abnormalities in the DNA repair pathway directly affect the outcome of radiotherapy and chemotherapy in lung cancer (28-30), since radiotherapy and the majority of first-line chemotherapeutic drugs kill tumor cells mainly through DNA damage (12).

SCLC commonly shows sensitivity to initial chemotherapy and radiotherapy with $>50 \%$ remission rate, yet radiation or drug resistance quickly develops, The disease usually relapses or progresses within 1 year (2). Therefore, abnormal overexpression of FIGNL1 indicates abnormal enhancement of the DNA double-strand repair system which may be one of the main mechanisms underlying the clinical features of SCLC as mentioned above.

As shown above, a significant increase in $\mathrm{H} 446$ cell sensitivity to etoposide and cisplatin was found after FIGNL1 silencing. Indeed, the lower the FIGNL1 expression, the higher the sensitivity of cells to etoposide/cisplatin (DNA damaging agents). These results further support the previous notion that in SCLC, DNA double-strand break repair pathways are abnormally enhanced.

The mechanism of etoposide and cisplatin involving the induction of DNA damage is different. Etoposide functions by inactivating DNA topoisomerase II (31), whereas the action of cisplatin is due to its ability to promote intra-strand and interstrand crosslinking between adjacent purine bases of the DNA strand (32). Once topoisomerase II in tumor cells is inhibited by etoposide, DNA damage occurs immediately. However, for cisplatin, DNA damage in tumor cells may gradually occur and accumulate in DNA replication and transcription process after increasing DNA adducts are formed.

In the present study, FIGNL1 knockdown sensitized H446 cells to etoposide and cisplatin in different patterns (Tables II and III). For etoposide, the sensitization reached its highest level at an earlier stage ( $24 \mathrm{~h}$ ), while cisplatin showed an opposite pattern. In addition, there was an obvious positive correlation between the severity of DNA damage and sensitization. These results are consistent with the mechanism of these two chemotherapeutic agents. The results mentioned above were obtained using NCI-H446 cells, and may be verified in more SCLC cell lines, i.e. NCI-H1688, in future research.

DNA repair pathway abnormalities contribute directly to the main causes of the poor outcome of cancer treatment, i.e. chemoresistance, radioresistance and relapse $(28,29)$. Therefore, several studies aimed to identify targets of cancer therapy and biomarkers in the DNA repair pathway $(33,34)$. Although the cell cycle was not effected, FIGNL1 knockdown significantly inhibited the expression of cyclin E1 and CDK2. This implies that FIGNL1-mediated regulation of the expression of cell cycle genes may exist, and our future research aims to investigate the underlying mechanisms.

Based on the finding of the present study and studies from other investigators, we suggest that DNA double-strand break repair HR pathways are abnormally enhanced in SCLC and the activity can be markedly suppressed through manipulation of FIGNL1. Thus, FIGNL1 is a promising target for SCLC.

\section{Acknowledgements}

The present study was supported by grants from the Ministry of Agriculture in China (2012ZX08011002-004), the National Natural Science Foundation of China (31121064), and the State Key Laboratory of Microbial Metabolism (no. 2011DA105494).

\section{References}

1. Chapman CJ, Thorpe AJ, Murray A, Parsy-Kowalska CB, Allen J, Stafford KM, Chauhan AS, Kite TA, Maddison P and Robertson JF: Immunobiomarkers in small cell lung cancer: Potential early cancer signals. Clin Cancer Res 17: 1474-1480, 2011.

2. Mamdani H, Induru R and Jalal SI: Novel therapies in small cell lung cancer. Transl Lung Cancer Res 4: 533-544, 2015.

3. Halazonetis TD, Gorgoulis VG and Bartek J: An oncogene-induced DNA damage model for cancer development. Science 319: 1352-1355, 2008.

4. Schvartzman JM, Sotillo R and Benezra R: Mitotic chromosomal instability and cancer: Mouse modelling of the human disease. Nat Rev Cancer 10: 102-115, 2010.

5. Goode EL, Ulrich CM and Potter JD: Polymorphisms in DNA repair genes and associations with cancer risk. Cancer Epidemiol Biomarkers Prev 11: 1513-1530, 2002.

6. Yaglom JA, McFarland C, Mirny L and Sherman MY: Oncogenetriggered suppression of DNA repair leads to DNA instability in cancer. Oncotarget 5: 8367-8378, 2014.

7. Scott SP and Pandita TK: The cellular control of DNA doublestrand breaks. J Cell Biochem 99: 1463-1475, 2006. 
8. Jeggo PA and Löbrich M: How cancer cells hijack DNA double-strand break repair pathways to gain genomic instability. Biochem J 471: 1-11, 2015.

9. Helleday T, Petermann E, Lundin C, Hodgson B and Sharma RA: DNA repair pathways as targets for cancer therapy. Nat Rev Cancer 8: 193-204, 2008.

10. Pleasance ED, Stephens PJ, O'Meara S, McBride DJ, Meynert A, Jones D, Lin ML, Beare D, Lau KW, Greenman C, et al: A small-cell lung cancer genome with complex signatures of tobacco exposure. Nature 463: 184-190, 2010.

11. Byers LA, Wang J, Nilsson MB, Fujimoto J, Saintigny P, Yordy J, Giri U, Peyton M, Fan YH, Diao L, et al: Proteomic profiling identifies dysregulated pathways in small cell lung cancer and novel therapeutic targets including PARP1. Cancer Discov 2: 798-811, 2012.

12. Damia G and D'Incalci M: Targeting DNA repair as a promising approach in cancer therapy. Eur J Cancer 43: 1791-1801, 2007.

13. Hine CM, Seluanov A and Gorbunova V: Use of the Rad51 promoter for targeted anti-cancer therapy. Proc Natl Acad Sci USA 105: 20810-20815, 2008.

14. Richardson C, Stark JM, Ommundsen M and Jasin M: Rad51 overexpression promotes alternative double-strand break repair pathways and genome instability. Oncogene 23: 546-553, 2004.

15. Cox GA, Mahaffey CL, Nystuen A, Letts VA and Frankel WN: The mouse fidgetin gene defines a new role for AAA family proteins in mammalian development. Nat Genet 26: 198-202, 2000.

16. Luke-Glaser S, Pintard L, Tyers M and PeterM:The AAA-ATPase FIGL-1 controls mitotic progression, and its levels are regulated by the CUL-3 ${ }^{\mathrm{MEL}-26} \mathrm{E} 3$ ligase in the C. elegans germ line. J Cell Sci 120: 3179-3187, 2007.

17. L'Hôte D, Vatin M, Auer J, Castille J, Passet B, Montagutelli X, Serres $C$ and Vaiman D: Fidgetin-likel is a strong candidate for a dynamic impairment of male meiosis leading to reduced testis weight in mice. PLoS One 6: e27582, 2011.

18. Yuan $\mathrm{J}$ and Chen $\mathrm{J}$ : FIGNL1-containing protein complex is required for efficient homologous recombination repair. Proc Natl Acad Sci USA 110: 10640-10645, 2013.

19. Hartwell LH and Kastan MB: Cell cycle control and cancer. Science 266: 1821-1828, 1994.

20. Rajagopalan $\mathrm{H}$ and Lengauer $\mathrm{C}$ : Aneuploidy and cancer. Nature 432: 338-341, 2004.
21. Lupas AN and Martin J: AAA proteins. Curr Opin Struct Biol 12: 746-753, 2002.

22. Hanson PI and Whiteheart SW: AAAt proteins: Have engine, will work. Nat Rev Mol Cell Biol 6: 519-529, 2005.

23. Tucker PA and Sallai L: The AAA+ superfamily - a myriad of motions. Curr Opin Struct Biol 17: 641-652, 2007.

24. Snider J and Houry WA: AAA+ proteins: Diversity in function, similarity in structure. Biochem Soc Trans 36: 72-77, 2008

25. Wendler P, Ciniawsky S, Kock M and Kube S: Structure and function of the AAA+ nucleotide binding pocket. Biochim Biophys Acta 1823: 2-14, 2012.

26. Yachida S, Jones S, Bozic I, Antal T, Leary R, Fu B, Kamiyama M, Hruban RH, Eshleman JR, Nowak MA, et al: Distant metastasis occurs late during the genetic evolution of pancreatic cancer. Nature 467: 1114-1117, 2010.

27. Heaphy CM, Bisoffi M, Joste NE, Baumgartner KB, Baumgartner RN and Griffith JK: Genomic instability demonstrates similarity between DCIS and invasive carcinomas. Breast Cancer Res Treat 117: 17-24, 2009.

28. O'Grady S, Finn SP, Cuffe S, Richard DJ, O'Byrne KJ and Barr MP: The role of DNA repair pathways in cisplatin resistant lung cancer. Cancer Treat Rev 40: 1161-1170, 2014.

29. Willers H, Azzoli CG, Santivasi WL and Xia F: Basic mechanisms of therapeutic resistance to radiation and chemotherapy in lung cancer. Cancer J 19: 200-207, 2013.

30. Peters GJ, Avan A, Ruiz MG, Orsini V, Avan A, Giovannetti E and Smit EF: Predictive role of repair enzymes in the efficacy of Cisplatin combinations in pancreatic and lung cancer. Anticancer Res 34: 435-442, 2014.

31. Eastman A: The formation, isolation and characterization of DNA adducts produced by anticancer platinum complexes. Pharmacol Ther 34: 155-166, 1987.

32. Hurwitz JL, McCoy F, Scullin P and Fennell DA: New advances in the second-line treatment of small cell lung cancer. Oncologist 14: 986-994, 2009.

33. Martin SA, Lord CJ and Ashworth A: DNA repair deficiency as a therapeutic target in cancer. Curr Opin Genet Dev 18: 80-86, 2008.

34. Madhusudan S and Middleton MR: The emerging role of DNA repair proteins as predictive, prognostic and therapeutic targets in cancer. Cancer Treat Rev 31: 603-617, 2005. 